\title{
Optimasi Asam Glikolat dan Asam Sitrat dalam Krim Tabir Surya Kombinasi Titanium Dioksida, Avobenzone, dan Octyl Methoxycinnamate
}

\section{(Optimization of Glycolic Acid and Citric Acid in Sunscreen Cream Combination of Titanium Dioxide, Avobenzone, and Octyl Methoxycinnamate)}

\author{
Lidya Ameliana, Dwi Nurahmanto, Desy Diana Sari \\ Fakultas Farmasi Universitas Jember \\ Jln. Kalimantan 37, Jember 68121 \\ e-mail korespondensi: lidyaameliana@unej.ac.id
}

\begin{abstract}
Ultraviolet (UV) radiation is the main cause of sunburn and skin cancer. The adverse effects of UV radiation are solved by sunscreen as protection for longer outdoors. In this study, optimization of glycolic acid and citric acid in sunscreen cream combination of titanium dioxide, avobenzone, and octyl methoxycinnamate were investigated using simplex lattice design method. The sunscreen cream evaluation includes physicochemical testing (organoleptic, homogeneity, emulsion type, spreadability, viscosity, and $\mathrm{pH}$ ) and sunscreen effectiveness (SPF, \% erythema transmission, and \% pigmentation transmission). The value of physicochemical testing are $5,96 \mathrm{~cm}-6,3 \mathrm{~cm}$ of spreadability testing; 83,33 $\mathrm{dPa}$.s - 108,33 dPa.s of viscosity testing; 4,06 - 4,67 of $\mathrm{pH}$ testing. The value of sunscreen effectiveness are $9,79-13,35$ of SPF testing; $4,55 \times 10^{-06}-0,15 \times 10^{-06} \%$ of \% erythema transmission; $5,77-7,16 \%$ of $\%$ pigmentation transmission. The optimum formula was obtained by combining glycolic acid $2 \%$ and citric acid $0 \%$ with a desirability value of 0,649 .
\end{abstract}

Keywords: sunscreen, SPF, glycolic acid, citric acid

\begin{abstract}
Abstrak
Sinar ultraviolet (UV) merupakan penyebab utama dari sunburn dan kanker kulit. Efek negatif dari sinar UV tersebut perlu diatasi dengan penggunaan tabir surya sebagai perlindungan saat berada di luar ruangan lebih lama. Pada penelitian ini telah dilakukan optimasi komposisi asam glikolat dan asam sitrat dalam krim tabir surya kombinasi titanium dioksida, avobenzone dan octyl methoxycinnamate dengan metode simplex lattice design. Evaluasi sediaan krim tabir surya yang dihasilkan meliputi sifat fisika kimia (organoleptis, homogenitas, tipe krim, daya sebar, viskositas dan $\mathrm{pH}$ ) dan efektivitas in vitro tabir surya (SPF, persen transmisi eritema, persen transmisi pigmentasi). Hasil uji sifat fisika kimia meliputi uji daya sebar berada pada rentang 5,96 cm - 6,3 cm; uji viskositas berada pada rentang 83,33 dPa.s - 108,33 dPa.s; uji pH berada pada rentang 4,06 - 4,67. Hasil uji efektivitas in vitro tabir surya meliputi uji SPF

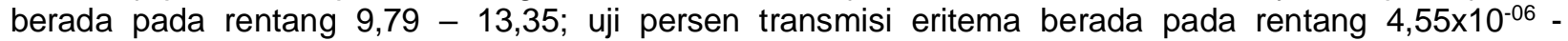
$0,15 \times 10^{-06}$; uji persen transmisi pigmentasi berada pada rentang $5,77-7,16$. Formula optimum yang diperoleh yaitu kombinasi asam glikolat $2 \%$ dan asam sitrat $0 \%$ dengan nilai desirability sebesar 0,649 .
\end{abstract}

Kata kunci: tabir surya, SPF, asam glikolat, asam sitrat 


\section{Pendahuluan}

Matahari dapat memancarkan radiasi dalam berbagai panjang gelombang, salah satunya yaitu sinar ultraviolet (UV). Sinar UV dibagi menjadi UVA, UVB, dan UVC [1]. Paparan sinar UV yang berlebihan dapat menimbulkan efek berbahaya pada kulit seperti eritema, sunburn, dan tanning [2]. Efek dari sinar UV tersebut perlu diatasi dengan adanya sediaan tabir surya.

Sediaan tabir surya adalah suatu sediaan kosmetik yang berfungsi mangabsorbsi secara efektif sinar matahari terutama pada wilayah gelombang UV sehingga dapat mencegah terjadinya gangguan kulit [3]. Titanium dioksida $\left(\mathrm{TiO}_{2}\right)$ sebagai physical blocker bekerja dengan memantulkan sinar UV [4,5]. Avobenzone memberikan daya serap tertinggi sepanjang spektrum UV-A serta octyl methoxycinnamate (OMC) mampu menstabilkan avobenzone dalam jangka waktu yang lama serta menambah stabilitas fotosensitif dari avobenzone [6].

Alpha Hydroxy Acid (AHA) adalah asam karboksilat dengan gugus hidroksi pada pada posisi alfa [7]. AHA sebagai antioksidan dan keratinisasi yang berfungsi untuk mengatasi sunburn, eritema, hiperpigmentasi [8]. AHA yang dipilih dalam penelitian ini adalah asam sitrat dan asam glikolat. Asam glikolat juga sebagai anti inflamasi dengan bertindak sebagai antioksidan pada kerusakan kulit yang parah [9]. Asam sitrat berfungsi sebagai antioksidan dan pengatur $\mathrm{pH}$ [10]. Asam sitrat dapat menginduksi kolagen I dan prokolagen II dan dapat meningkatkan pembaharuan kulit serta mengobati kulit yang rusak akibat sinar matahari [8].

Pada penelitian ini, optimasi asam glikolat dan asam sitrat dalam krim tabir surya kombinasi titanium dioksida, avobenzone, dan octyl methoxycinnamate dalam basis vanishing cream menggunakan metode simplex lattice design dilakukan untuk mengetahui nilai komposisi optimum dan pengaruh asam glikolat dan asam sitrat serta kombinasinya terhadap efektivitas secara in vitro (nilai SPF, \%transmisi eritema, \%transmisi pigmentasi), viskositas, dan $\mathrm{pH}$ sediaan krim tabir surya.

\section{Metode Penelitian}

Penelitian ini menggunakan metode simplex lattice design dengan skala laboratorium yang dilakukan di Laboratorium Farmasetika Fakultas Farmasi Universitas Jember.

Alat yang digunakan dalam penelitian ini adalah spektrofotometer UV-Vis (Genesys 10S), $\mathrm{pH}$ meter digital (Elmetron CP-502), neraca analitik (Adventure Ohaus), alat penguji viskositas (Viskotester VT04), mikroskop optik (Olympus DP21), program design expert versi 11, ekstensometer, hot plate, mortir dan stemper, serta alat-alat gelas.

Bahan yang digunakan dalam penelitian ini adalah avobenzone (Vivimed Laba Ltd), OMC (Chemspec Chemical Pvt. Ltd), setil alkohol (PT.Brataco Chemical), asam stearat (PT.Brataco Chemical), titanium dioksida (Huntsman, Italy), nipagin (PT.Brataco Chemical), nipasol (PT.Brataco Chemical), tween 80 (PT. Makmur Jaya), trietanolamin, dimetikon, propilen glikol (PT.Brataco Chemical), asam sitrat (PT.Brataco Chemical), asam glikolat (CABB $\mathrm{GmbH}$ ), isopropanol (PT.Brataco Chemical), methylene blue dan aquades (PT. Makmur Jaya).

Ketiga formula pada penelitian ini mengandung bahan aktif tabir surya dan bahan tambahan yang sama dengan konsentrasi yang juga sama kecuali konsentrasi asam glikolat dan asam sitrat yang berbeda pada tiap formula mengikuti model simplex lattice design (SLD) yang dapat dilihat pada Tabel 1.

Tabel 1. Rancangan Formula Penelitian

\begin{tabular}{cccc}
\hline Faktor & $\mathrm{F}(1)$ & $\mathrm{F}(2)$ & $\mathrm{F}(3)$ \\
\hline Asam Glikolat & 1 & 0,5 & 0 \\
Asam Sitrat & 0 & 0,5 & 1 \\
\hline
\end{tabular}

Pembuatan krim tabir surya dilakukan dengan mencampurkan fase minyak (avobenzone, OMC, setil alkohol, dimetikon, asam stearat, dan nipasol) dan fase air (tween 80, propilen glikol, nipagin, TEA, akuades) pada cawan yang berbeda kemudian dipanaskan pada suhu $70{ }^{\circ} \mathrm{C}$ di atas hotplate. Campuran tersebut diaduk hingga meleleh dan homogen. Setelah itu fase minyak dan fase air dimasukkan pada mortir hangat sambil diaduk secara konstan sampai terbentuk masa krim. Kemudian ditambahkan titanium oksida, asam glikolat dan asam sitrat sambil terus diaduk sampai diperoleh krim yang homogen.

Evaluasi sediaan krim tabir surya meliputi evaluasi sifat fisika kimia dan efektivitas 
in vitro. Evaluasi sifat fisika kimia meliputi pengujian organoleptis, homogenitas, tipe krim, $\mathrm{pH}$, viskositas, dan daya sebar. Evaluasi efektivitas in vitro meliputi penentuan nilai SPF, \%transimisi eritema (\%TE), dan \%transmisi pigmentasi (\%TP). Data hasil penelitian viskositas, $\mathrm{pH}$, SPF, \%TE, dan \%TP kemudian dianalisis statistik dengan program SPSS versi 22.0.

Data hasil pengujian kemudian dijadikan respon yang diolah menggunakan program perangkat lunak design expert versi 11 untuk mendapatkan persamaan $\mathrm{Y}=\mathrm{Ba}(\mathrm{A})+\mathrm{Bb}(\mathrm{B})+$ $\mathrm{Bab}(\mathrm{A})(\mathrm{B})$ sehingga didapatkan persamaan hubungan antara faktor (konsentrasi asam glikolat dan asam sitrat) dan respon $(\mathrm{pH}, \mathrm{SPF}$, $\%$ transmisi pigmentasi, dan \% transmisi eritema) dari krim tabir surya. Dari persamaan tersebut dapat dibuat contour plot dengan menggunakan program perangkat lunak design expert versi 11. Contour plot tersebut kemudian digabung sehingga didapatkan titik potong yang merupakan formula optimum.

\section{Hasil Penelitian}

Hasil pembuatan krim tabir surya dapat dilihat pada Gambar 1. Hasil pengujian organoleptis menunjukkan bahwa ketiga formula krim tabir surya memiliki tekstur lembut, berwarna putih dan tidak berbau. Hasil pengujian homogenitas menunjukkan ketiga formula memiliki susunan yang homogen dan tidak terlihat adanya butiran kasar. Hasil pengujian tipe krim menunjukkan ketiga formula memiliki tipe krim minyak dalam air (m/a). Hasil pengujian daya sebar, viskositas, pH, SPF, \%TE dan \%TP krim tabir surya dapat dilihat pada Tabel 2, Tabel 3, dan Tabel 4.

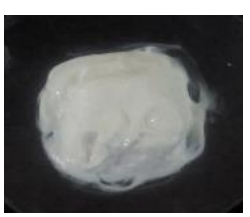

(a)

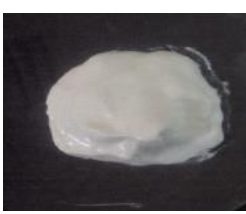

(b)

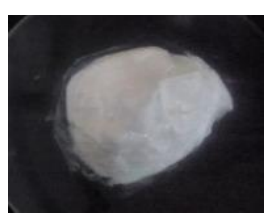

(c)
Gambar 1. Hasil pembuatan krim tabir surya
Tabel 2. Hasil pengujian daya sebar dan viskositas

\begin{tabular}{ccc}
\hline Formula & $\begin{array}{c}\text { Daya Sebar } \\
(\mathrm{cm})\end{array}$ & $\begin{array}{c}\text { Viskositas } \\
(\mathrm{dPa} . \mathrm{S})\end{array}$ \\
\hline $\mathrm{F}(1)$ & $6,30 \pm 0,10$ & $83,33 \pm 2,887$ \\
\hline $\mathrm{F}(2)$ & $5,96 \pm 0,15$ & $108,33 \pm 2,887$ \\
\hline $\mathrm{F}(3)$ & $6,23 \pm 0,15$ & $91,67 \pm 2,887$ \\
\hline
\end{tabular}

Tabel 3. Hasil pengujian pH dan SPF

\begin{tabular}{ccc}
\hline Formula & $\mathrm{pH}$ & $\mathrm{SPF}$ \\
\hline $\mathrm{F}(1)$ & $4,29 \pm 0,015$ & $12,53 \pm 0,404$ \\
\hline $\mathrm{F}(2)$ & $4,67 \pm 0,020$ & $9,79 \pm 0,177$ \\
\hline $\mathrm{F}(3)$ & $4,06 \pm 0,021$ & $13,35 \pm 0,280$ \\
\hline
\end{tabular}

Tabel 4. Hasil pengujian \%TE dan \%TP

\begin{tabular}{ccc}
\hline Formula & $\% \mathrm{TE}$ & $\% \mathrm{TP}$ \\
\hline $\mathrm{F}(1)$ & $4,53 \times 10^{-06} \pm 1,60 \times 10^{-06}$ & $6,64 \pm 0,1929$ \\
\hline $\mathrm{F}(2)$ & $0,16 \times 10^{-06} \pm 1,49 \times 10^{-06}$ & $5,77 \pm 0,2983$ \\
\hline$F(3)$ & $4,09 \times 10^{-06} \pm 1,62 \times 10^{-06}$ & $7,16 \pm 0,2079$ \\
\hline
\end{tabular}

\section{Analisis Data dengan Metode Simplex Lattice Design}

Hasil analisis uji viskositas krim tabir surya pada Tabel 2 menunjukkan bahwa $F(1)<F(3)<F(2)$. Nilai viskositas krim tabir surya $F(1)$ paling kecil dibandingkan formula lainnya sehingga dapat dikatakan sediaan krim akan mudah dikeluarkan dari tube tetapi sulit untuk mengendalikan pengeluaran krim untuk dioleskan pada kulit.

Hasil analisis viskositas krim tabir surya menggunakan design expert versi 11 diperoleh persamaan sebagai berikut :

\section{Final Equation in Terms of Real Components : Viskositas $1=+83,75000^{*}$ asam glikolat $+91,25000^{*}$ asam sitrat $+85,00000^{*}$ asam glikolat*asam sitrat}

Final Equation in Terms of Actual Components : Viskositas $_{2}=+41,87500^{*}$ asam glikolat $+45,62500 \mathrm{~B}$ *asam sitrat $+21,25000^{*}$ asam glikolat*asam sitrat

Persamaan tersebut menjelaskan pengaruh asam glikolat dan asam sitrat serta kombinasinya terhadap respon viskositas. Berdasarkan persamaan tersebut didapatkan hasil contour plot viskositas. Hasil contour plot viskositas dapat dilihat pada Gambar 2. 


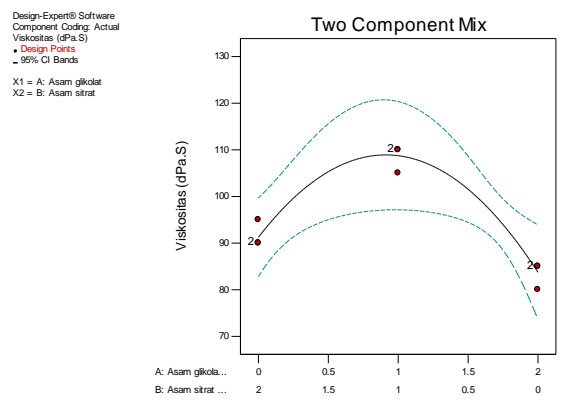

Gambar 2. Contour plot viskositas

Hasil analisis uji pH krim tabir surya pada Tabel 3 menunjukkan bahwa $\mathrm{F}(3)<\mathrm{F}(1)<\mathrm{F}(2)$. Hasil analisis $\mathrm{pH}$ krim tabir surya menggunakan design expert versi 11 diperoleh persamaan sebagai berikut :

Final Equation in Terms of Real Components : $\mathrm{pH}_{1}=+4,30500 *$ asam glikolat $+4,05500^{*}$ asam sitrat $+1,96000^{*}$ asam glikolat*asam sitrat

Final Equation in Terms of Actual Components : $\mathrm{pH}_{2}=+2,15250^{*}$ asam glikolat $+2,02750^{*}$ asam sitrat $+0,49000^{*}$ asam glikolat*asam sitrat

Persamaan tersebut menjelaskan pengaruh asam glikolat dan asam sitrat serta kombinasinya terhadap respon $\mathrm{pH}$. Berdasarkan persamaan tersebut didapatkan hasil contour plot $\mathrm{pH}$. Hasil contour plot $\mathrm{pH}$ dapat dilihat pada Gambar 3.

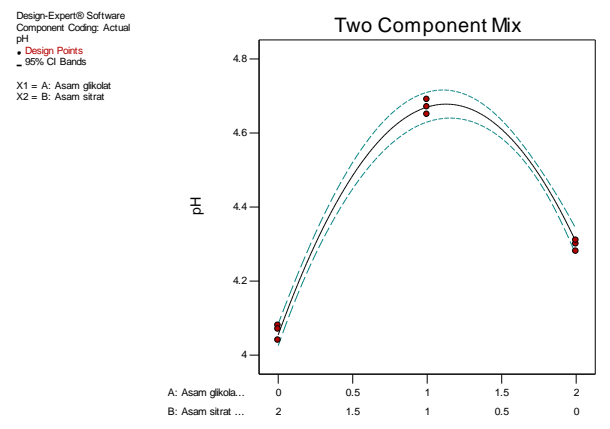

Gambar 3. Contour plot pH

Hasil analisis uji SPF krim tabir surya pada Tabel 3 menunjukkan bahwa nilai SPF krim tabir surya $F(3)>F(1)>F(2)$. Krim tabir surya pada $F(3)$ menunjukkan nilai SPF paling besar dibandingkan formula lainnya sehingga lebih baik dalam melindungi kulit dari sinar UV. Hasil analisis uji SPF krim tabir surya pada program design expert versi 11 diperoleh persamaan berikut:

Final Equation in Terms of Real Components :

$\mathrm{SPF}_{1}=+12,28625^{\star}$ asam glikolat $+13,32625^{\star}$ asam sitrat $-11,20000^{*}$ asam glikolat*asam sitrat

Final Equation in Terms of Actual Components : $\mathrm{SPF}_{2}=+6,14313^{*}$ asam glikolat $+6,66313^{*}$ asam sitrat $-2,80000^{\star}$ asam glikolat ${ }^{\star}$ asam sitrat

Persamaan tersebut menjelaskan pengaruh asam glikolat dan asam sitrat serta kombinasinya terhadap respon SPF. Berdasarkan persamaan tersebut didapatkan hasil contour plot SPF. Hasil contour plot SPF dapat dilihat pada Gambar 4.

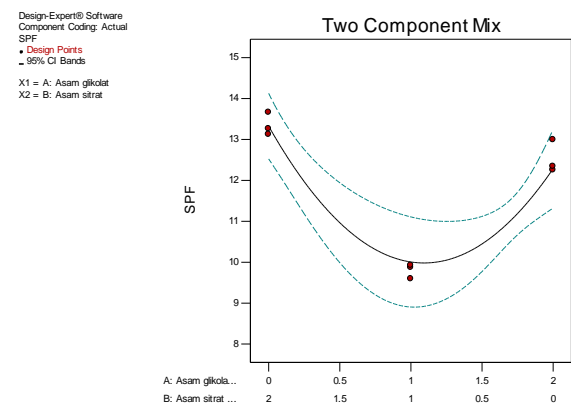

Gambar 4. Contour plot SPF

Hasil analisis uji \%TE krim tabir surya pada Tabel 4 menunjukkan bahwa $F(1)<F(3)<F(2)$. Nilai \%TE krim tabir surya $F(1)$ paling kecil dibandingkan formula lainnya sehingga lebih baik dalam melindungi kulit dari sinar UV penyebab eritema. Hasil analisis uji \%TE krim tabir surya pada program design expert versi 11 diperoleh persamaan berikut:

Final Equation in Terms of Real Components : $\% \mathrm{TE}_{1}=+5,03750 \mathrm{E}-006^{*}$ asam glikolat $+4,63750 \mathrm{E}$ $006^{*}$ asam sitrat $+4,10800 \mathrm{E}-005^{\star}$ asam glikolat*asam sitrat

Final Equation in Terms of Actual Components : $\% \mathrm{TE}_{2}=+2,51875 \mathrm{E}-006 *$ asam glikolat $+2,31875 \mathrm{E}-$ $006^{*}$ asam sitrat $+1,02700 \mathrm{E}-005^{*}$ asam glikolat*asam sitrat 
Berdasarkan persamaan tersebut didapatkan hasil contour plot \%TE. Hasil contour plot \%TE dapat dilihat pada Gambar 5.

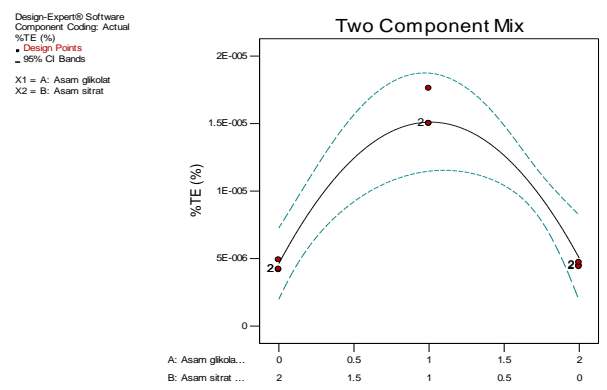

Gambar 5. Contour plot \%TE

Hasil analisis uji \%TP krim tabir surya pada Tabel 4 menunjukkan bahwa nilai \%TP krim tabir surya $F(2)$ paling kecil dibandingkan formula lainnya, sehingga lebih baik dalam melindungi kulit dari sinar UV penyebab pigmentasi. Hasil analisis uji \%TP krim tabir surya pada program design expert versi 11 diperoleh persamaan berikut:

Final Equation in Terms of Real Components : $\% \mathrm{TP}_{1}=+6,54750^{*}$ asam glikolat $+7,02250^{*}$ asam sitrat $-3,41000^{*}$ asam glikolat*asam sitrat

Final Equation in Terms of Actual Components : $\% \mathrm{TP}_{2}=+3,27375^{\star}$ asam glikolat $+3,51125^{\star}$ asam sitrat $-0,85250^{\star}$ asam glikolat ${ }^{*}$ asam sitrat

Persamaan tersebut menjelaskan pengaruh asam glikolat dan asam sitrat serta kombinasinya terhadap respon \%TP. Berdasarkan persamaan tersebut didapatkan hasil contour plot \%TP. Hasil contour plot \%TP dapat dilihat pada Gambar 6.

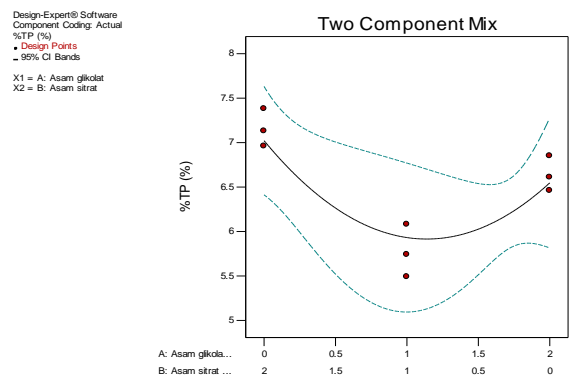

Gambar 6. Contour plot \%TP

\section{Pembahasan}

Hasil pengujian daya sebar pada Tabel 2 menunjukkan ketiga formula memiliki daya sebar yang baik, yakni antara 5-7 cm [11]. Daya sebar $F(1)$ memiliki daya sebar paling besar dibandingkan formula lain sebab viskositas pada $F(1)$ paling kecil dibandingkan formula lain. Viskositas berbanding terbalik dengan daya sebar krim tabir surya, semakin besar viskositas maka daya sebarnya semakin kecil [12]. Hasil pengujian viskositas pada Tabel 2 menunjukkan ketiga formula memiliki viskositas yang baik, yakni antara 50-150 dPa.s [12].

Berdasarkan persamaan yang didapatkan dari design expert untuk respon viskositas menunjukkan nilai koefisien asam sitrat lebih besar dari asam glikolat yang berarti asam sitrat lebih berpengaruh dalam meningkatkan respon viskositas daripada asam glikolat. Koefisien kombinasi asam glikolat dan asam sitrat menunjukkan nilai positif serta pada Gambar 2 menunjukkan kurva melengkung ke atas yang berarti kombinasi asam glikolat dan asam sitrat dapat meningkatkan respon viskositas.

Hasil pengujian $\mathrm{pH}$ pada Tabel 3 menunjukkan ketiga formula memiliki $\mathrm{pH}$ yang sesuai dengan $\mathrm{pH}$ yang diinginkan yaitu pada rentang 3,5 - 5,5 [13,14]. Berdasarkan persamaan yang didapatkan dari design expert untuk respon $\mathrm{pH}$ menunjukkan nilai koefisien asam glikolat lebih besar dari asam sitrat yang berarti asam glikolat lebih berpengaruh dalam meningkatkan respon $\mathrm{pH}$ daripada asam sitrat. Koefisien kombinasi asam glikolat dan asam sitrat menunjukkan nilai positif serta pada Gambar 3 menunjukkan kurva melengkung ke atas yang berarti kombinasi asam glikolat dan asam sitrat dapat meningkatkan respon $\mathrm{pH}$.

Hasil pengujian SPF pada Tabel 3 menunjukkan ketiga formula memiliki SPF dengan kategori proteksi maksimal, yaitu memiliki nilai SPF pada rentang 8-15 [15]. Berdasarkan persamaan yang didapatkan dari design expert untuk respon SPF menunjukkan nilai koefisien asam sitrat lebih besar dari asam glikolat yang berarti asam sitrat lebih berpengaruh dalam meningkatkan respon SPF daripada asam glikolat. Koefisien kombinasi asam glikolat dan asam laktat menunjukkan nilai negatif serta pada Gambar 4 menunjukkan kurva melengkung ke bawah yang berarti 
kombinasi asam glikolat dan asam sitrat dapat menurunkan respon SPF.

Hasil pengujian \%TE pada Tabel 4 menunjukkan ketiga formula memiliki \%TE dengan kategori sunblock, yaitu \%TE $<1 \%$ [16]. Berdasarkan hasil ANOVA, persamaan, dan Gambar 5 yang diperoleh dari program design expert menunjukkan bahwa asam glikolat dan asam sitrat serta kombinasinya tidak signifikan dalam meningkatkan respon \%TE.

Hasil pengujian \%TP pada Tabel 4 menunjukkan ketiga formula memiliki \%TP dengan kategori sunblock, yakni antara 3-40\% [16]. Berdasarkan persamaan yang didapatkan dari design expert untuk respon \%TP menunjukkan nilai koefisien asam glikolat lebih besar dari asam sitrat yang berarti asam glikolat lebih berpengaruh dalam meningkatkan respon \%TP daripada asam sitrat. Koefisien kombinasi asam glikolat dan asam sitrat menunjukkan nilai negatif serta pada Gambar 6 menunjukkan kurva melengkung ke bawah yang berarti kombinasi asam glikolat dan asam sitrat dapat menurunkan respon \%TP.

Gugus hidroksi bebas dari asam sitrat dan gugus karboksilat dari asam glikolat dapat mengalami reaksi kondensasi membentuk surfaktan anionik berupa ester karboksilat dengan $\mathrm{pH}$ netral atau basa [17], yang keberadaannya dapat meningkatkan $\mathrm{pH}$ sediaan krim tabir surya. Suasana asam akan menyebabkan pergeseran panjang gelombang maksimum ke panjang gelombang yang lebih kecil [18]. Semakin besar nilai pH maka panjang gelombang maksimumnya akan lebih besar dibandingkan panjang gelombang maksimum pada $\mathrm{pH}$ yang lebih kecil sehingga nilai SPF dan persen TP in vitro akan menurun.

Formula optimum diperoleh

berdasarkan hasil contour plot dari semua respon sehingga akan membentuk kurva komposisi formula versus desirability. Kurva hubungan antara formula versus desirability dapat dilihat pada Gambar 7. Nilai desirability semakin mendekati angka 1 maka semakin dekat formula optimum tersebut terhadap kriteria nilai respon yang diharapkan. Kriteria respon yang diharapkan yaitu respon viskositas berada pada rentang 50-150 dPa.s dan respon $\mathrm{pH}$ berada pada rentang 3,5-5,5. Kriteria untuk respon SPF yaitu semakin besar nilai SPF maka semakin baik. Kriteria untuk respon \%TE dan
\%TP yaitu semakin kecil \%TE dan \%TP maka semakin baik.

Solusi merupakan titik formula optimum yang ditunjukkan dengan adanya perpotongan antara komposisi asam glikolat dan asam sitrat dengan desirability. Terdapat tiga solusi yang muncul pada program Design Expert versi 11 seperti yang ditunjukkan pada Gambar 8, tetapi solusi yang dipilih adalah solusi yang memiliki nilai desirability paling mendekati 1. Nilai desirability formula optimum yang dipilih yaitu 0 , 649. Komposisi asam glikolat $2 \%$ dan asam sitrat $0 \%$ memberikan respon (viskositas, $\mathrm{pH}$, SPF, persen TE, dan persen TP) paling optimum dengan nilai prediksi respon viskositas 83,75 d.Pa.s; respon $\mathrm{pH}$ 4,305; respon SPF 12,286, respon persen TE 0,00000409\%, respon persen TP $6,548 \%$.

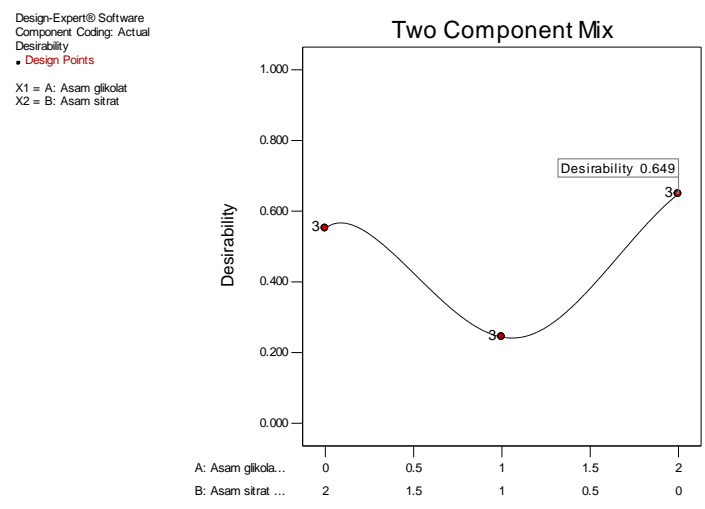

Gambar 7. Kurva hubungan komposisi versus desirability

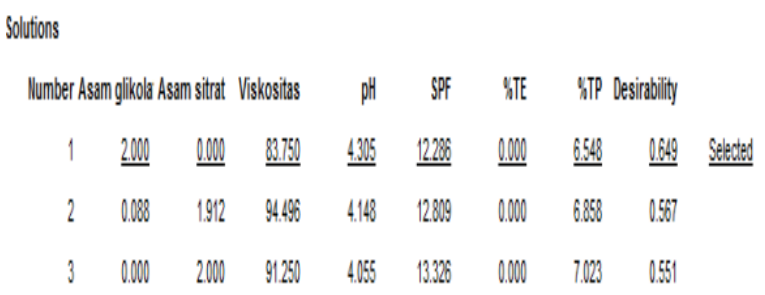

Gambar 8. Solusi formula optimum

\section{Simpulan dan Saran}

Asam glikolat dan asam sitrat serta kombinasinya tidak berpengaruh signifikan dalam menaikkan respon \%TE in vitro. Asam sitrat berpengaruh lebih besar dalam meningkatkan respon viskositas, nilai SPF, dan 
\%TP dibandingkan asam glikolat; sedangkan asam glikolat berpengaruh lebih besar dalam meningkatkan respon $\mathrm{pH}$ dibandingkan asam sitrat. Kombinasi asam glikolat dan asam sitrat dapat meningkatkan respon viskositas dan $\mathrm{pH}$ sediaan serta menurunkan respon nilai SPF dan \%TP in vitro sediaan krim tabir surya yang mengandung bahan aktif titanium dioksida, avobenzone, dan octyl methoxycinnamate.

Komposisi asam glikolat $2 \%$ dan asam sitrat $0 \%$ memberikan respon (viskositas, $\mathrm{pH}$, SPF, \%TE, dan \%TP) paling optimum pada sediaan krim tabir surya yang mengandung bahan aktif titanium dioksida, avobenzone, dan octyl methoxycinnamate.

Penelitian selanjutnya diharapkan dapat dilakukan uji efektivitas in vivo, uji stabilitas dan uji iritasi sediaan krim tabir surya kombinasi titanium dioksida, avobenzone, dan octyl methoxycinnamate dengan penambahan asam glikolat dan asam sitrat. Selain itu, perlu dilakukan uji verifikasi terhadap formula optimum yang dihasilkan.

\section{Ucapan Terima Kasih}

Penulis mengucapkan terima kasih kepada Bagian Farmasetika Fakultas Farmasi Universitas Jember yang telah memberikan dukungan dalam penyelesaian penelitian.

\section{Daftar Pustaka}

[1] Cahyono WE. Dampak peningkatan radiasi ultraviolet b. Peneliti Bidang Pengkajian Ozon Dan Polusi Udara, LAPAN. 2005. 7(1):22-26.

[2] Ekowati D. dan Hanifah IR. Potensi tongkol jagung ( zea mays I.) sebagai sunscreen dalam sediaan hand body lotion. Jurnal Ilmiah Manuntung. 2016. 2(2):198-207.

[3] Rejeki S dan Wahyuningsih SS. Formulasi Gel Tabir Surya Minyak Nyamplung (Tamanu Oil) Dan Uji Nilai Spf Secara In Vitro. University Research Colloquium, 2015. 97-103.

[4] Serpone N, Salinaro A, Emeline AV, Horikoshi S, Hidaka H, dan Zhao J. An in vitro systematic spectroscopic examination of the photostabilities of a random set of commercial sunscreen lotions and their chemical uvb/uva active agents. Photochemical and Photobiological
Sciences. 2002. 1(12):970-981.

[5] Gilbert E, Pirot F, Bertholle V, Roussel L, Falson F, dan Padois K. Commonly used uv filter toxicity on biological functions: review of last decade studies. International Journal of Cosmetic Science. 2013. 35(3):208-219.

[6] Palm MD. dan O'Donoghue MN. Update on photoprotection. Actas DermoSifiliograficas. 2007. 101(8):659-672.

[7] Van Scott EJ, Ditre CM, dan Yu RJ. Alphahydroxyacids in the treatment of signs of photoaging. Clinics in Dermatology. 1996. 14(2):217-226.

[8] Tang SC. dan Yang JH. Dual effects of alpha-hydroxy acids on the skin. Molecules. 2018. 23(4):1-12.

[9] Tung RC, Bergfeld WF, Vidimos AT, dan Remzi BK. a-hydroxy acid-based cosmetic procedures: guidelines for patient management. American Journal of Clinical Dermatology. 2000. 1(2):81-88.

[10] Green BA, Yu RJ, Van Scott EJ. Clinical and cosmeceutical uses of hydroxyacids. Clinics in Dermatology. 2009. 27(5): 495501.

[11] Susanti dan Kusmiyarsih. Formulasi dan uji stabilitas krim ekstrak etanolik daun bayam dusri (amaranthus spinosus I.). Jurnal Biomedika. 2012. 5(1):1-12.

[12] Martin A, Swarbrick J, dan Cammarata A. Farmasi Fisik. Edisi Ketiga. Jilid 2. Jarkarta: Universitas Indonesia Press. 1993.

[13] Barel A, Paye $M$, dan Maibach $H$. Handbook of Cosmetic Science and Technology, Second Edition. New York: Marcel Dekker, Inc. 2006.

[14] Sudarsono ML. Optimasi Titanium Dioksida dan Zink Oksida Sebagai Physical Blocker dalam Krim Tabir Surya Kombinasi Benzophenon-3 dan Octyl Methoxycinnamate. Skripsi. Jember: Fakultas Farmasi Universitas Jember. 2017.

[15] Harry RG. Harry's Cosmeticology. Seventh edition. London: Leonard Hill Book. 1982.

[16] Soeratri W, Ifansyah N, dan Unair FF. Penentuan persentase transmisi eritema dan pigmentasi beberapa minyak atsiri. Berk. Penel. Hayati. 2005. 10:117-121. 
Ameliana, et al, Optimasi Asam Glikolat dan Asam Sitrat dalam Krim Tabir Surya ......

[17] Athiyah M, Ahmad I, dan Rijai L. Aktivitas tabir surya ekstrak akar Bandotan (Ageratum conysoides L.). Jurnal Sains Dan Kesehatan, 2015. 1(4), 181-187.
[18] Shaath NA. The Chemistry Of Sunscreens. In: N.J. Lowe and N.A. Shaath (Eds). Sunscreen: Development, Evaluatiom, and Regulatory Aspects. New York: Marcel Dekker, Inc. 1990. 